\title{
Body Response to Local Muscular Performance of Individuals Engaged in Various Professional Occupations
}

\author{
Olga G. Kourova1, Tatiana V. Popova1, Yury I. Koryukalov² \\ ${ }^{1}$ Department of Management and Business of South Ural State University, Chelyabinsk, Russia \\ ${ }^{2}$ Department of Food Engineering of South Ural State University, Chelyabinsk, Russia \\ Email: tvp@susu.ac.ru, tati.popova2010@yandex.ru, arhy82@mail.ru
}

Received 24 June 2014; revised 27 July 2014; accepted 18 August 2014

Copyright (C) 2014 by authors and Scientific Research Publishing Inc.

This work is licensed under the Creative Commons Attribution International License (CC BY). http://creativecommons.org/licenses/by/4.0/

c) (i) Open Access

\begin{abstract}
We have compared 142 adult men and women of various ages, grouped by professional occupation, all the occupations involving local muscular performance. We studied heart reactions and central nervous system reactions to local muscular performance done until fatigue set in. The results suggested that adaptive body changes had a number of shared signs, namely, tachycardia, hypertension, and increased statistical figures of the heart rhythm, which were indicative of tension in central regulatory mechanisms of the heart.
\end{abstract}

\section{Keywords}

Local Muscular Performance, Occupational Activity Adaptation, Functional Strain, Types of Adaptive Body Changes

\section{Introduction}

Depending on the muscle mass necessary to perform this or that work, human physical performance is classified into local, regional, and global physical performance. Local physical performance involves less than 1/3 of skeletal muscles, with the load primarily falling on the muscles of fingers, hands, and forearms. Intense local muscular performance is common in compositors, punch operators, machine tool operators, etc. [1]. Operators perform tens of thousands finest and highly differentiated motions at a rapid rate. The nature and the intensity of functional changes in workers' bodies are primarily determined by the total number of motions they perform per shift.

Sedentary lifestyle and emotional distresses are the reasons underlying nervous and mental diseases in opera- 
tors and causing occupational malfunctions that, in turn, may lead to emergencies.

Isometric muscular performance involves firm grip on tools, as well as maintaining fixed positions of the whole body or its parts. Longer tensions in muscles cause pronounced fatigue and neuromuscular apparatus disorders [2] [3]. Typing, managerial work, undergraduate studies, or medical manipulations performed by nurses - one can hardly think of any modern occupations that do not involve local muscular performance. The work conditions in those groups remain understudied, while some scholars keep reiterating that morbidity rate is high in those groups [4].

We repeatedly quoted the information about the pronounced pressor effect of local muscular performance in individuals of various ages, especially in relation to diastolic blood pressure [5], and put forward an assumption that the fatigue related to local muscular performance could be of central nature [6].

The objective of this work is to conduct research into the influence of local muscular performance on blood circulation and neurodynamic functions in the subjects of various occupations.

\section{Methods}

We examined groups of university students (15 males and 16 females) aged 18 to 22 (US), 19 female nurses (FN) aged 25 to 45, 18 female managers (FM) aged 25 to 35, machine tool operators (MTO) aged 20 to 40 (19 males and 15 females) and 2 groups of engineers (Eng) aged 30 to 40 (13 females and 12 males) and aged 60 to 70 (8 males and 7 females). All the above groups had shared local muscle groups involved in their occupational activities, with the longest (of up to $60 \%$ of their work time) and the most intense local muscular performance being most common in machine tool operators. We examined 142 subjects. We took into account that the number of older subjects were not so much, so calculate the statistical significance of these parameters using nonparametric statistics of Fisher for small samples. Statistics confirm the representativeness of the sample for all observations.

The research was conducted on a voluntary informed consent basis in compliance with the protocol approved by the Ethics Committee of the Russian Academy of Sciences.

In our earlier report [5], we justified the implementation of local endurance performance test, with endurance load optimal for every age group. Selecting between endurance performance values, we decided on an "average load” (according to Ernst Heinrich Weber [7]) that imposed the heaviest endurance performance per lift. The local endurance performance test was in lifting a load of 1/3 of the "average load" at the rate of 60 to 70 lifts per minute by means of a Mosso ergograph. The local isometric performance test was in holding out a load of $1 / 3$ of the maximum load at a specified level by means of a Mosso ergograph or a hand dynamometer until fatigue set in (that is, until a subject felt unable to hold the specified load any longer). With the test conditions thus specified, most of the subjects demonstrated the endurance performance of 1 to 2 minutes. The criterion for fatigue was a verbal declaration by a subject that he/she was unable to continue the test.

We measured the local endurance performance until fatigue set in by seconds. The performance parameters recorded before and after the local endurance performance test were as follows: the heart rate, the blood pressure (by means of a blood pressure monitor), the heart rhythm variability (recorded by means of a ECG-cardiointervalogram R-R), with further statistic analysis of heart rate structure according to Bayevskiy [8]. We subjected to computer analysis the following: (Mo) - the average value of the predicted R-R interval in ms; MxDMn (TINN) - the difference between the maximum and the minimum R-R, (AMo) - the conventional index of activity sympathetic component regulation; and tension index (TI)—-the formula AM/Mo x 2M x DMn in units. AMo and TI parameters were indicative of the activity of the central mechanisms of heart regulation. We used NS-Psycho-Test Plus toolkit to study the neurodynamic properties [9]. The technique made it possible to measure the rate of motor reactions to a simple visual stimulus (№ 1), to the selection of either visual stimuli (№ 2), the performance rate of various motor reactions to two dissimilar stimuli (№ 3), the reaction rate of visual stimulus with static trammels (№ 4), to a visual stimulus with dynamic trammels (№ 5), and the reaction rate of attention allocation reaction when searching numbers from 1 to 25 (№ 6).

\section{Results}

The results of the research suggested that an increase in heart rate, blood pressure, and statistical figures of heart rhythm pattern, which were indicative of elevated tension in central mechanisms of heart regulation (AMo mode amplitude and tension index TI), were recorded in all the age and occupational groups, following local muscular performance (see Table 1). It is noteworthy that heart rate reactions were more pronounced in the group of young males than in that of young females, while the rest of the groups demonstrated almost no gender differen- 
Table 1. Changes in functional properties of cardiovascular system under local dinamic muscle load.

\begin{tabular}{|c|c|c|c|c|c|c|c|c|c|c|}
\hline \multirow{3}{*}{$\begin{array}{l}\text { Age } \\
\text { groups }\end{array}$} & \multicolumn{10}{|c|}{ Indicator } \\
\hline & \multicolumn{2}{|c|}{ Heart rate, $\mathrm{bpm}^{-1}$} & \multicolumn{2}{|c|}{ SYS, mmHg } & \multicolumn{2}{|c|}{ DIA, mmHg. } & \multicolumn{2}{|c|}{ Amo, \% } & \multicolumn{2}{|c|}{ TI, conv. Units } \\
\hline & 1 & 2 & 1 & 2 & 1 & 2 & 1 & 2 & 1 & 2 \\
\hline \multirow{2}{*}{$\begin{array}{c}18-20 \\
\text { US }\end{array}$} & $70.3 \pm 3.4$ & $79.5 \pm 2.5^{*}$ & $120.7 \pm 5.2$ & $124.3 \pm 4.7$ & $75.0 \pm 3.4$ & $82.1 \pm 3.4$ & $44.3 \pm 4.2$ & $50.0 \pm 3.8$ & $173 \pm 9.8$ & $220 \pm 10.0^{*}$ \\
\hline & $78.6 \pm 4.3^{* *}$ & $81.9 \pm 3.7$ & $108.0 \pm 5.3$ & $113.0 \pm 6.7$ & $76.9 \pm 2.3$ & $78.0 \pm 4.8$ & $39.3 \pm 4.1$ & $33.8 \pm 3.6^{* *}$ & $103 \pm 11.0^{* *}$ & $119 \pm 8.5^{* *}$ \\
\hline \multirow{2}{*}{$\begin{array}{c}30-40 \\
\text { ETP }\end{array}$} & $63.3 \pm 2.5$ & $68.8 \pm 3.8$ & $121.7 \pm 4.1$ & $125.0 \pm 3.5$ & $75.0 \pm 3.4$ & $75.0 \pm 4.2$ & $43.5 \pm 3.8$ & $42.0 \pm 3.7$ & $115 \pm 11.0$ & $110 \pm 9.1$ \\
\hline & $70.4 \pm 3.0^{* *}$ & $72.1 \pm 2.7^{* *}$ & $106.9 \pm 3.8$ & $113.9 \pm 5.2$ & $76.9 \pm 4.8$ & $78.8 \pm 4.2$ & $42.3 \pm 2.7$ & $49.0 \pm 4.0$ & $138 \pm 10.0$ & $221 \pm 12.0^{* *}$ \\
\hline \multirow{2}{*}{$\mathrm{P}$} & $<0.05$ & $<0.05$ & $>0.5$ & $>0.5$ & $>0.5$ & $>0.5$ & $>0.5$ & $>0.5$ & $<0.05$ & $<0.05$ \\
\hline & $>0.5$ & $<0.05$ & $>0.5$ & $>0.5$ & $>0.5$ & $>0.5$ & $>0.5$ & $<0.05$ & $<0.05$ & 0.05 \\
\hline \multirow{2}{*}{$\begin{array}{c}60-70 \\
\text { ETP }\end{array}$} & $74.3 \pm 3.7$ & $77.5 \pm 3.2$ & $124.0 \pm 7.2$ & $135.0 \pm 6.8$ & $75.0 \pm 4.2$ & $75.4 \pm 2.8$ & $49.3 \pm 5.2$ & $51.0 \pm 4.0$ & $210 \pm 12.0$ & $290 \pm 13.0^{*}$ \\
\hline & $81.3 \pm 2.9^{* *}$ & $85.6 \pm 3.5^{* *}$ & $135.0 \pm 5.4$ & $145.0 \pm 6.3$ & $78.8 \pm 4.2$ & $81.4 \pm 3.5$ & $45.4 \pm 3.6$ & $41.0 \pm 4.5$ & $138 \pm 9.5^{* *}$ & $142 \pm 8.7^{* *}$ \\
\hline \multirow{2}{*}{$\mathrm{P}$} & $<0.05$ & $<0.05$ & $>0.5$ & $>0.5$ & $>0.5$ & $>0.5$ & $>0.5$ & $>0.5$ & $<0.05$ & $<0.05$ \\
\hline & $<0.05$ & $<0.05$ & $<0.05$ & $<0.05$ & $>0.5$ & $>0.5$ & $>0.5$ & $>0.5$ & $>0.5$ & $<0.05$ \\
\hline
\end{tabular}

Note: 1 -before; 2 - after work; first line across—-men; second—women; *-marks the difference between 1and 2; **_-between men and women; $\mathrm{P}$ - shows proper difference against the previous group.

tiation as to heart rate reactions and blood pressure reactions.

The highest functional heart tension was recorded in groups of male students and engineers aged 60 to 70 (Heart rate more than $70.3 \pm 3.4 \mathrm{bpm}$ ), in combination with higher heart rate at rest than in subjects aged 30 to 35 (Heart rate $<70.4 \pm 3.0 \mathrm{bpm}$ ). Multidirectional changes in AMo and TI rates were recorded in females, which was indicative of unsatisfactory heart adaptations to local muscular performance, according to [10], while the longest duration of local muscular performance until fatigue set in was recorded in male students (104 $\pm 3.7 \mathrm{sec})$ and the shortest one-in males aged 60 to 70 (83 $\pm 4.6 \mathrm{sec})$.

It is noteworthy that elevated activity in central mechanisms of heart regulation according to [8] was recorded in all the subjects, especially in young males, and elderly males. Functional heart tension, on the contrary, was higher in females (TI $138 \pm 10.0$ conv. units) than in males (TI $115 \pm 11.0$ conv. units) in the age group of 30 to 40 .

Neurodynamic properties differed from occupation to occupation in groups of similar ages (see Table 2). Female nurses demonstrated more rapid psychomotor actions that female managers, except for discrimination reaction.

All the subjects had a shared complex of physical and psychoemotional load. The occupational activities of nurse, however, involved both a higher specific gravity of local muscular performance and considerable psychoemotional tension while at work. Manual operations performed by nurses required higher motor skill rate and attention, as well as responsibility.

Fatigue onset throughout a work day was higher in nurses than in managers. By the end of a workday, static hand endurance reduced on average by $18 \pm 2.4 \mathrm{sec}$ from $(\mathrm{P}<0.05)$ in nurses, and by $9 \pm 1.9 \mathrm{sec}$ from $(\mathrm{P}>0.5)$ in managers.

The groups of machine tool operators were subjected to a longer occupational local muscular performance, which made it possible to assess adaptive changes in their bodies. Examinations were made over a year, prior to the commencement of work, an hour before a lunch break, and an hour before shift end. The results did not suggest that there were any significant differences between isometric hand endurance in males and in females.

\section{Discussion}

While taking into account the nature of the dynamics of the functional changes, we classified adaptive body changes related to job tension into three types. Type one, “optimal”, had static endurance duration from 80 seconds onwards, tension index of up to 100 conventional units, heartbeat rate of 60 to 75 beats per minute ${ }^{-1}$, and blood pressure reaction to local muscular performance of 10 to $20 \mathrm{~mm}$ of mercury; type two, "satisfactory”, had static endurance duration of 40 to 60 seconds, tension index of up to 150 conventional units, heartbeat rate of 75 to 85 beats per minute ${ }^{-1}$, and blood pressure reaction of 20 to $30 \mathrm{~mm}$ of mercury; and type three, “unsatis- 
Table 2. Indicators of neurotest among the subjects of different professions.

\begin{tabular}{|c|c|c|c|c|c|c|}
\hline \multirow{2}{*}{ Group } & \multicolumn{6}{|c|}{ Tests, Ms } \\
\hline & 1 & 2 & 3 & 4 & 5 & 6 \\
\hline $\begin{array}{l}\text { Managers female. } \\
\text { before work, } n=18\end{array}$ & $443.4 \pm 12.2$ & $508.6 \pm 13.3$ & $387.4 \pm 12$ & $414.7 \pm 16.4$ & $481.7 \pm 15.4$ & $2041.6 \pm 25.4$ \\
\hline Managers female, after work. & $454.2 \pm 10.3$ & $488.3 \pm 11.2$ & $437.3 \pm 13.1^{*}$ & $458.5 \pm 12.2^{*}$ & $505.4 \pm 13.2$ & $2267.3 \pm 20.1^{*}$ \\
\hline Nurses before work, $\mathrm{n}=19$ & $290.1 \pm 12.3$ & $407.1 \pm 13$ & $508.2 \pm 15.4$ & $364.3 \pm 19.8$ & $375 \pm 19.5$ & $1481.1 \pm 34.2$ \\
\hline Nurses after work shift & $331.1 \pm 10.2^{*}$ & $437.2 \pm 13.8^{*}$ & $528 \pm 14.2$ & $486.1 \pm 12.5^{*}$ & $391.2 \pm 11.2$ & $1700.5 \pm 19.8^{*}$ \\
\hline
\end{tabular}

Note: 1-simple hand-to-eye reaction; 2-reaction of choice; 3-reaction of differentiation; 4-hand-to-eye reaction of choice with static interference; 5 - hand-to-eye reaction of choice with dynamic interference; 6 - reaction to the distribution of attention; *-proper difference against the previous line.

factory”, had static endurance duration of less than 40 seconds, tension index exceeding 150 conventional units, heartbeat rate exceeding 85 beats per minute ${ }^{-1}$, and blood pressure reaction exceeding $30 \mathrm{~mm}$ of mercury.

Thus, local physical work done until fatigue sets in, may be used as an independent performance unit to assess general or occupational fatigue.

When small muscle groups worked, fatigue set in very soon, in just 1.5 to 3 minutes, which made it possible to assess functions of various body systems meanwhile. According to our research, the nature of heart reactions to local muscular performance correlated with the general functional body state that depended on the central nervous system state.

We discovered unsatisfactory type of adaptive body changes in $16 \%$ of male and $55 \%$ of female machine tool operators. It is noteworthy that the female machine tool operators had had longer average work experience duration (of 5 to 10 years) than male machine tool operators ( 1 to 5 years). Accordingly, the average age in the female group ( $37.2 \pm 3.8$ ) was 5 years older than in the male group (32.4 \pm 4.1$)$. Hypertensive syndrome was discovered in 5 females and 3 males aged 30 to 40 .

Therefore, fatigue during local muscular performance manifests itself through pronounced functional tension, decrease in functional reserves, and the onset of hypertensive syndrome. Various research groups attributed the onset of fatigue caused by local muscular performance to hormonal shifts [10] or cerebral metabolic dysfunctions [11]. The function of serotonin in the central mechanisms behind the onset of fatigue was also explained [10]. In our earlier research, we suggested [6] that pronounced changes in bioelectrical activity in the alpha rhythm area of cerebral cortex occurred when performing local muscular exercises. The data of this and the earlier researches suggest that the activity level of the central regulatory mechanisms increases as fatigue sets in during local muscular exercises.

The mechanism of pressor reactions during local muscular performance is related to reflex influences exerted by metabolic receptors of active muscles, which caused redistribution of vascular tone and changes in blood pressure similar to those described in the report [12]. Predominance of rapid motor units in hand muscles also affects the nature of heart reactions when those muscles contract, possibly, by means of ergoreceptors [13].

\section{Conclusions}

The results of numerous researches into physical and mental fatigue [14] [15] suggested that physical and mental endurance were closely interrelated, on the basis of which the researchers also proved that fatigue was of central nature [2]. Dissimilar understandings of the nature of fatigue caused by local muscular performance provided dissimilar approaches to fatigue prophylaxis and prevention.

We propose, e.g., to apply magnet therapy on fatigued muscles [16] or to use beta-blockers to prevent cerebral metabolic dysfunctions [10]. We tested the action of psychophysical relaxation exercises [17] that, if performed systematically, alleviated functional tension, and reduced heartbeat rate and blood pressure shifts due to local muscular exercises (or performance).

Research conducted by [18] [19] discovered that the reserve for performing fine and gross motor assignments and motor skill exercises increased, following relaxation sessions. The data [6] that we obtained be means of EEG suggested that excitation in the CNS restored rapidly, and so did excitation and inhibition processes in the subjects, following relaxation sessions. 
All in all, our research suggests that local muscle exercise cause a heart reaction that manifests itself trough an increase in heartbeat rate, all blood pressure figures, and tension index — the latter reflects the elevated functional activity of heart regulation in all the subjects. Longitudinal research of individuals involved in operating machine tools over a year suggests that the type of heart reactions to local performance depends on the general body state that, in turn, depends on both the work experience duration and the fatigue degree.

\section{References}

[1] Donskaya, L. (1979) Local Muscle Load as the Problem of Occupational Physiology. Successes Physiol. Science. T. 10. Number 1, p. 85.

[2] Amann, M. and Dempsey J.A. (2008) Locomotor Muscle Fatigue Modifies Central Motor Drive in Healthy Humans and Imposes a Limitation to Exercise Performance. The Journal of Physiology, 586, 161-173.

[3] Gambashidze, G.M., Tkhorevsky, V.I. and Yampol'skaya, E.G. (1985) Functional Condition of the Person with Monotonous Activity with Different Physical Activity. Hygiene and Occupational Diseases. Number 6, p. 5.

[4] Winokur, V.A. (2002) Occupational Stress among Nurses. Herald MAPE, 4-7.

[5] Alferova (Popova) T.V. (1998) Age Features of the Circulatory Response to Local Muscle Activity of Static and Dynamic Character. Advances of Physiological Sciences, 19, 54-75.

[6] Popova, T.V. (2007) Central Mechanisms of Fatigue during Local Muscle Activity Static Nature. Human Physiology, T. 33, 95-100.

[7] Weber, E.H. and Handworterb, W. (1846) Der Physiologye, 3, 481.

[8] Baevskii, R.M. and Kukushkin Y.A. (1995) Methodology of Assessing the Functional State of the Human Body. Occupational Medicine and Industrial Ecology. № 3, p. 30.

[9] Morocco, D.A. Computer Program for Psychoneurological Testing. Certificate of Official Registration of Computer Software Number 2007610943 from 1 March 2007. The Registry of the Computer Programs of the Russian Federation.

[10] Larsen, T.S., Rasmussen, P., Overgaard, M., Secher, N.H. and Nielsen, H.B. (2007) Non-Selective Beta-Adrenergic Blockade Prevents Reduction of the Cerebral Metabolic Ratio during Exhaustive Exercise in Humans. The Journal of Physiology, 586, 281-296.

[11] Meeusen, R., Watson, P., Hasegawa, H., Roelands, B. and Piacentini, M.F. (2006) Central Fatigue. The Serotonin Hypothesis and Beyond. Sports Medicine, 36, 881-909.

[12] Fisher, J.P., Adlan, A.M., Shantsila, A., Secher, J.F., et al. (2013) Muscle Metaboreflex and Autonomic Regulation of Heart Rate in Humans. Journal of Physiology, 3777-3788.

[13] Gandevia, S.C. and Hobbs S.F. (1990) Cardiovascular Responses to Static Exercise in Man: Central and Reflex Contributions. The Journal of Physiology, 430, 105-117.

[14] Kayse, B. (2003) Exercise Starts and Ends in the Brain. European Journal of Applied Physiolog, 90, 411-419.

[15] Marcora, S.M., Staiano, W. and Manning, V. (2009) Mental Fatigue Impairs Physical Performance in Humans. Journal of Applied Physiology, 3, 857-864.

[16] Loschilov, V.N. (2006) The Influence of the Alternating Magnetic Field on Human Muscle Performance during Local and General Tiredness. Human Physiology, 32, 696-700.

[17] Popova, T.V. (2007) Self-Regulation of Functional States. South Ural State University, Chelyabinsk, 156 p.

[18] French, S. (1977) Electromyographic. Biofeedback for Tension Control during Fine and Gross Motor Skill Acquisition. Unpublished Doctoral Dissertation, Oregon State University.

[19] Owen, H. and Lanning, W. (1982) The Effects of Three Treatment Methods upon Anxiety and Inappropriate AttenHigh School Athletes. International Journal of Sport Psychology, 30, 154-162. 
Scientific Research Publishing (SCIRP) is one of the largest Open Access journal publishers. It is currently publishing more than 200 open access, online, peer-reviewed journals covering a wide range of academic disciplines. SCIRP serves the worldwide academic communities and contributes to the progress and application of science with its publication.

Other selected journals from SCIRP are listed as below. Submit your manuscript to us via either submit@scirp.org or Online Submission Portal.
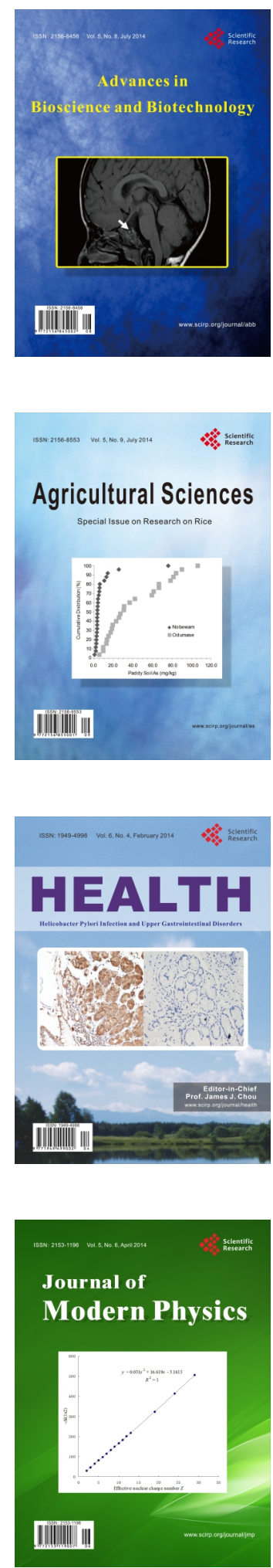
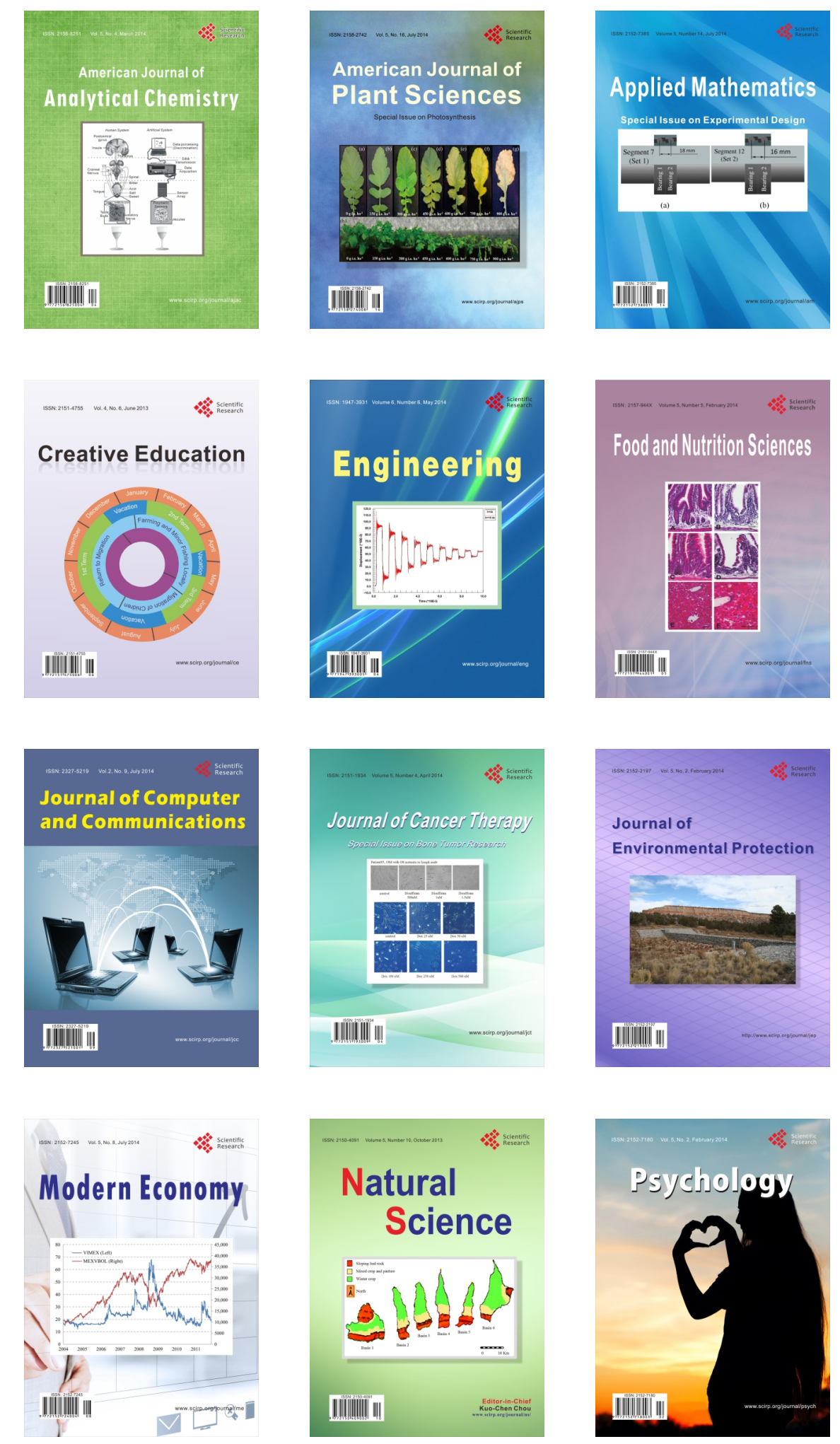